\title{
High Risk Behavior, Knowledge and Attitude of HIV/AIDS among Workers in Factories Manufacturing Alcohol in Mandalay, Myanmar
}

\author{
Khin Thiri Maung', Htoo Htoo Kyaw Soe ${ }^{2 *}$, Nan Nitra Than ${ }^{2}$, Simerjit Singh Madan², Senthil Kumar P. ${ }^{2}$ \\ ${ }^{1}$ College of Public Health Sciences, Chulalongkorn University, Bangkok, Thailand; ${ }^{2}$ Faculty of Medicine, Melaka-Manipal Medical \\ College, Melaka, Malaysia. \\ Email: "htoo2ks@gmail.com
}

Received February $18^{\text {th }}, 2013$; revised March $20^{\text {th }}, 2013$; accepted March $28^{\text {th }}, 2013$

Copyright (C) 2013 Khin Thiri Maung et al. This is an open access article distributed under the Creative Commons Attribution License, which permits unrestricted use, distribution, and reproduction in any medium, provided the original work is properly cited.

\begin{abstract}
Analytical cross-sectional study was conducted in Mandalay, Myanmar to identify high risk sexual behavior, knowledge and attitude regarding HIV/AIDS and prevention practice related to HIV/AIDS among male workers in factories manufacturing alcohol. Participants included male workers $(\mathrm{n}=219)$ from 10 alcohol factories in Industrial Zone (A). Data were collected through face to face interviews using pretested structured questionnaire. Results showed that $38.8 \%$ of the respondents were able to get discount to buy alcohol from their factory, and $70.3 \%$ of them consumed alcohol in the last 12 months. Regarding high risk sexual behavior, $38.4 \%$ of the respondents had intercourse with a casual partner of opposite gender, while $31.5 \%$ had intercourse with commercial sex workers and $19.2 \%$ had homosexual relationship during last 12 months. Among the married, $45 \%$ had extramarital intercourse. More than $80 \%$ of the respondents received HIV/AIDS related information from media and colleagues while $51.1 \%$ of them received from NGOs or health education at workplace. Among the respondents who engaged in different high risk sexual behaviors, $50 \%-88.9 \%$ did not use condom consistently and they had significantly lower knowledge about HIV/AIDS. However, the knowledge and attitude regarding HIV/AIDS were not significantly different between the respondents who used condom consistently and those who did not. This study highlights the need of health education about HIV/AIDS and access to affordable condoms among workers in factories manufacturing alcohol to improve their knowledge, attitude and behavior, as well as to promote consistent condom usage as it is vital for prevention and control of HIV/AIDS.
\end{abstract}

Keywords: HIV/AIDS; Workers; Mandalay; Myanmar

\section{Introduction}

HIV/AIDS has remained a threat to human society for over three decades [1] since its discovery in early 1981 [2]. Global summary of HIV epidemics at the end of year 2010 estimated 34 (31.6 - 35.2) million people living with HIV and 1.8 (1.6 - 1.9) million people died due to AIDS [3]. In South East Asia, Myanmar is one of the most serious HIV/AIDS epidemic regions as HIV/AIDS is now ranked as first in nation's top three priority diseases [4]. In 2011, the national prevalence of HIV infection in adult population aged $15-49$ was $0.6 \%$ and an estimated 16,000 people died of AIDS related illness [5].

${ }^{*}$ Corresponding author.
HIV infection rate is highest in the working age group and it primarily kills the young and middle aged adults during their peak productive years [6]. Workplace is an important part of the life in this age group as they spend most of their time at workplace. In recent years, HIV/ ADIS is also believed to be workplace phenomenon because it has the potential to affect labor and productivity, and also the workplace can play a vital role in the wider struggles to limit the spread of epidemic. Some of the work related factors such as mobility of workers and separation away from families can increase the risk of HIV infection [7].

Myanmar is a conservative country with strong cultural norms regarding sexual behavior. As a result, research to identify priorities has many challenges. Knowledge and 
prevention of HIV/AIDS has been identified in sex workers, adolescent and young adult population and drug users $[8,9]$. Though knowledge, attitude and beliefs of sexual behavior regarding HIV/AIDS are important part of HIV/AIDS prevention [10], these have not been examined among workers in factories manufacturing alcohol. Therefore, we conducted a cross-sectional study to identify the high risk sexual behavior, knowledge and attitude about HIV/AIDS and prevention practice related to HIV/AIDS among male workers in factories manufacturing alcohol in Mandalay, Myanmar.

\section{Methods}

\subsection{Study Design and Setting}

Analytical cross-sectional study was conducted in Mandalay, Myanmar from January to April 2012. Mandalay is the second largest city of Myanmar having an estimated population of 1 million [11]. The industrial zone in Mandalay is divided into two parts: Industrial Zone (A) and Industrial Zone (B).

\subsection{Sample Size and Sampling}

Industrial Zone (A) was purposively selected as most of the alcohol factories are located. In this zone, there were about 486 male workers from 10 alcohol factories. The required sample size was calculated using Yamane formula [12] and was found to be 219. Proportional sampling method was used and the sample from each subgroup was collected in proportion to actual size of the group in the total population. After getting permission from factory owners/managers, the participants were selected by using simple random sampling. The male workers who were aged between 18 to 49 years and willing to participate were included.

\subsection{Data Collection}

Data were collected through face to face interviews using structured questionnaire. The questionnaire consisted of five parts including socio-demographic and occupational characteristics, knowledge and attitude about HIV/AIDS, sexual behavior and preventive practice such as consistent condom use. The questionnaire was prepared in English language and then translated into Burmese language. Pretest was done with 30 male workers in alcohol factories from Industrial Zone (A), and the validity and reliability of the questionnaire were checked. The content validity was checked by three experts. Cronbach's alpha coefficient for knowledge questions was 0.84 and attitude questions was 0.72 . Interviews were conducted at workplace by the researcher and trained health volunteers from local non-government organization.

\subsection{Statistical Analysis}

Data were analyzed using SPSS 12.0 version. Regarding knowledge and attitude, scores were computed by taking the sum. Descriptive statistic such as frequency, percentage, mean, standard deviation and bar chart were described wherever appropriate. Independent sample $\mathrm{T}$ test was used to identify the relationship between knowledge, attitude and high risk sexual behavior and consistent condom use. All tests were two-sided and the level of significance was set at 0.05 .

\subsection{Ethical Consideration}

Before the interview, the purpose and procedure of the study were explained to the respondents. Participation was voluntary and informed consent was obtained from each respondent. Confidentiality was maintained and anonymity of responses was ensured. In addition, the interview was held in private place that was away from managers/owners. Data were kept secured and made available only to the data analyst. All the study procedures were approved by Ethical Review Committee for Research Involving Human Research Subjects, Health Sciences Group, Chulalongkorn University, Bangkok, Thailand.

\section{Results}

\subsection{Description of Study Population}

A total of 219 male alcohol factory workers aged between 19 to 49 years participated in this study. Among the respondents, $47.9 \%$ were aged $21-30$ years while $10 \%$ were younger than 20 years. Single respondents comprised more than half $(53.4 \%)$ of the population. Regarding education, $78.5 \%$ of them completed at least high school education and $56.6 \%$ of them were from the study area, Mandalay. $76.7 \%$ of the respondents were living with their family and relatives, while 8.25 and $15.1 \%$ were staying alone or with their friends respectively. $31.1 \%$ of the respondents mentioned that they usually travelled out of town for job. Total monthly income ranged from 25 to 350 USD and $74 \%$ of the respondents had monthly income less than 100 USD (data not shown). $38.8 \%$ of them mentioned that they were able to get discount to buy alcohol from their factory (Table 1).

\subsection{Sources of HIV/AIDS Related Information}

All the study participants were asked about HIV/AIDS, its transmission and prevention. More than $80 \%$ of the respondents received HIV/AIDS related information from media such as television, poster, newspaper and magazine. Similarly, $86.8 \%$ mentioned that they also received that information from friends and colleagues. 
However, $51.1 \%$ of them received HIV/AIDS related health education from non-government organizations (NGOs) while $58.4 \%$ received health education at the workplace (Table 2). Among the respondents, $86.8 \%$ could mention the places from where they could get condom (data not shown).

Table 1. Socio-demographic and occupational characteristics of respondents $(n=219)$.

\begin{tabular}{lc}
\hline \multicolumn{1}{c}{ Variables } & Frequency (\%) \\
\hline Age & $22(10.0)$ \\
$19-20$ & $105(47.9)$ \\
$21-30$ & $68(31.2)$ \\
$31-40$ & $24(10.9)$ \\
$>40$ & \\
Mean $\pm \mathrm{SD}=29.7 \pm 7.5$, range $=19-49$ & \\
Marital status & $117(53.4)$ \\
Single & $100(45.6)$ \\
Married & $2(1.0)$ \\
Divorced \& widowed & \\
& \\
Education & $5(2.3)$ \\
Primary education & $42(19.2)$ \\
Secondary education & $172(78.5)$ \\
High school \& above & \\
Hometown & \\
Mandalay division & $124(56.6)$ \\
Other states \& divisions & $95(43.4)$ \\
& \\
Living with & \\
Alone & \\
Friends & \\
Family/relatives & $18(8.2)$ \\
Need to travel for job & $33(15.1)$ \\
Yes & $168(76.7)$ \\
No & \\
Eligible to buy alcohol with discount & \\
Yes & \\
No & $68(31.1)$ \\
& $151(68.9)$ \\
& \\
& \\
& \\
&
\end{tabular}

Table 2. Sources of HIV/AIDS related information $(n=219)$.

\begin{tabular}{lc}
\hline \multicolumn{1}{c}{ Variables } & Frequency (\%) \\
\hline Sources of information* & \\
Television & $204(93.2)$ \\
Poster & $199(90.9)$ \\
Newspaper & $197(90.0)$ \\
Magazine & $196(89.5)$ \\
Friends/colleagues & $190(86.8)$ \\
Family members & $163(74.4)$ \\
Workplace & $128(58.4)$ \\
NGOs & $112(51.1)$ \\
& \\
Sources of information at workplace (n $=\mathbf{1 2 8})^{*}$ & \\
Colleagues & $98(76.6)$ \\
Supervisor & $24(18.8)$ \\
Manager & $12(9.4)$ \\
Owner & $9(7.0)$ \\
\hline
\end{tabular}

*Multiple response answer.

\subsection{Sexual Behavior and Consistent Condom Use}

$70.3 \%$ of the respondents consumed alcohol when 3.7\% used illegal drugs in the last 12 months. While $54.5 \%$ of the respondents who consumed alcohol had intercourse after drinking, and $75 \%$ of the respondents who consumed illegal drug had intercourse after taking drug (Table 3).

Regarding high risk sexual behavior in the last 12 months, $38.4 \%$ of the respondents had intercourse with casual partner while $31.5 \%$ had intercourse with commercial sex workers and $19.2 \%$ had homosexual relationship. Among the married person, $45 \%$ had extramarital intercourse (Figure 1). The usage of condom among the respondents who engaged high risk sexual behavior is shown in Figure 2.

\subsection{Relationship between Knowledge, Attitude, High Risk Sexual Behavior and Consistent Condom Use}

Relationship between knowledge and attitude about HIV/ AIDS and high risk sexual behavior and consistent condom use is shown in Table 4. There was significant association of knowledge about HIV/AIDS and high risk

Table 3. Personal behavior and high risk sexual behavior (n = 219).

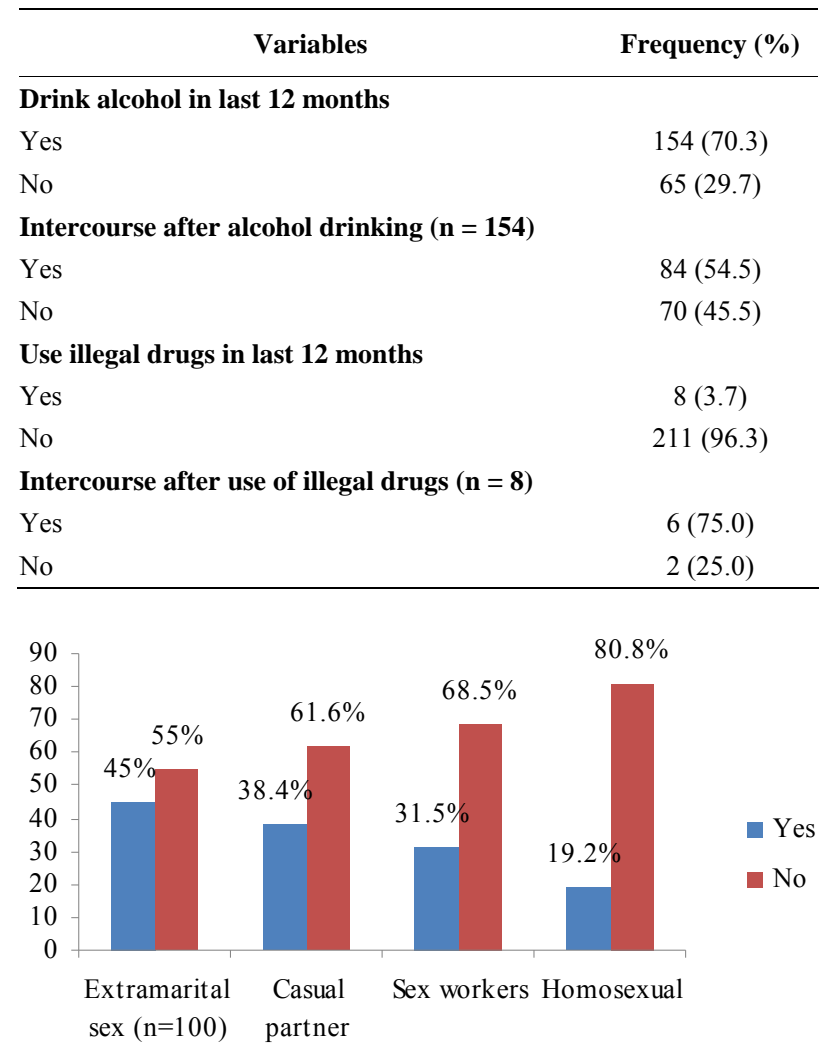

Figure 1. High risk sexual behavior among respondents in last 12 months $(n=219)$. 


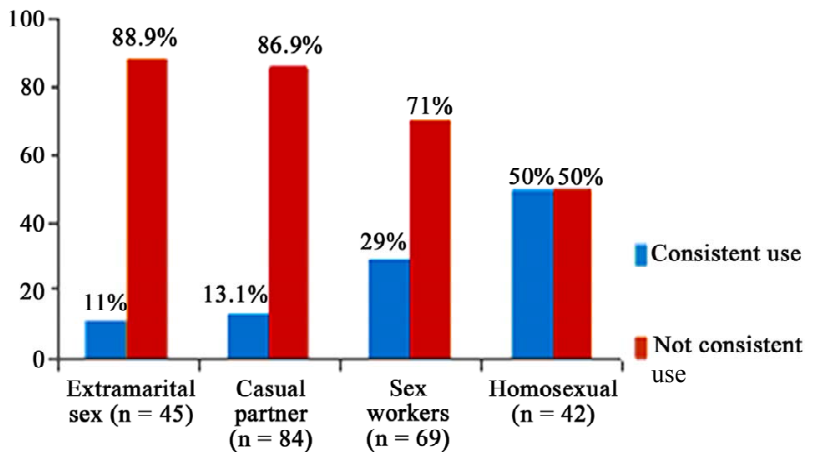

Figure 2. Consistent condom use among respondents who engaged high risk sexual behavior in last 12 months. sexual behavior. The respondents who engaged in high risk sexual behavior such as extramarital intercourse, intercourse with casual partner and commercial sex workers, and homosexual had significantly lower knowledge about HIV/AIDS. However, there was no significant difference of attitude between them (Table 5).

Table 4 reveals the relationship between knowledge and attitude and consistent condom use among the respondents who engaged high risk sexual behavior in the last 12 months. There was no significant difference regarding knowledge and attitude about HIV/AIDS between the respondents who used condom consistently and who did not use (Table 4).

Table 4. Relationship between knowledge and attitude about HIV/AIDS and consistent condom use in last 12 months.

\begin{tabular}{|c|c|c|c|c|c|c|c|}
\hline \multirow{2}{*}{ Variables } & \multirow{2}{*}{$\mathbf{N}(\%)$} & \multicolumn{3}{|c|}{ Knowledge } & \multicolumn{3}{|c|}{ Attitude } \\
\hline & & Mean \pm SD & $\mathbf{t}$ & P value & Mean \pm SD & $\mathbf{t}$ & $P$ value \\
\hline \multicolumn{8}{|c|}{ Consistent condom use in extramarital intercourse $(n=45)$} \\
\hline All the time & $5(11.1)$ & $25.40 \pm 2.702$ & -1.309 & 0.198 & $55.2 \pm 5.762$ & -1.861 & 0.07 \\
\hline Not all the time & $40(88.9)$ & $23.13 \pm 3.75$ & & & $49.65 \pm 6.339$ & & \\
\hline \multicolumn{8}{|c|}{ Consistent condom use with casual partner $(n=84)$} \\
\hline All the time & $11(13.1)$ & $23.55 \pm 4.083$ & -0.428 & 0.67 & $49.36 \pm 7.991$ & -0.194 & 0.847 \\
\hline Not all the time & $73(96.9)$ & $22.99 \pm 4.033$ & & & $48.93 \pm 6.719$ & & \\
\hline \multicolumn{8}{|c|}{ Consistent condom use with sex workers $(n=69)$} \\
\hline All the time & $20(9.1)$ & $24 \pm 4.365$ & -1.519 & 0.133 & $50.05 \pm 8.835$ & -0.421 & 0.675 \\
\hline Not all the time & $49(71)$ & $22.39 \pm 3.845$ & & & $49.24 \pm 6.457$ & & \\
\hline \multicolumn{8}{|c|}{ Consistent condom use in homosexual $(n=42)$} \\
\hline All the time & $21(50)$ & $23.19 \pm 4.25$ & -1.733 & 0.091 & $46.52 \pm 6.322$ & 0.603 & 0.55 \\
\hline Not all the time & $21(50)$ & $21 \pm 3.937$ & & & $47.62 \pm 5.417$ & & \\
\hline
\end{tabular}

$P$ value $<0.05$ is significant.

Table 5. Relationship between knowledge and attitude about HIV/AIDS and high risk sexual behavior in last 12 months (n = 219).

\begin{tabular}{|c|c|c|c|c|c|c|c|}
\hline \multirow{2}{*}{ Variables } & \multirow{2}{*}{ N (\%) } & \multicolumn{3}{|c|}{ Knowledge } & \multicolumn{3}{|c|}{ Attitude } \\
\hline & & Mean \pm SD & $\mathbf{t}$ & $P$ value & Mean \pm SD & $\mathbf{t}$ & P value \\
\hline \multicolumn{8}{|c|}{ Extramarital intercourse $(n=100)$} \\
\hline No & $45(45)$ & $25 \pm 4.082$ & & & $51.09 \pm 6.934$ & & \\
\hline \multicolumn{8}{|l|}{ Casual partner } \\
\hline Yes & $84(38.4)$ & $23.06 \pm 4.019$ & 2.596 & 0.01 & $48.99 \pm 6.847$ & 0.568 & 0.571 \\
\hline No & $135(61.6)$ & $24.48 \pm 3.894$ & & & $49.56 \pm 7.547$ & & \\
\hline \multicolumn{8}{|l|}{ Sex workers } \\
\hline Yes & $69(31.5)$ & $22.86 \pm 4.038$ & 2.758 & 0.006 & $49.48 \pm 7.349$ & -0.187 & 0.852 \\
\hline No & $150(68.5)$ & $24.43 \pm 3.887$ & & & $49.28 \pm 7.349$ & & \\
\hline \multicolumn{8}{|l|}{ Homosexual } \\
\hline Yes & $42(19.2)$ & $22.10 \pm 4.195$ & 3.402 & 0.001 & $47.07 \pm 5.841$ & 2.271 & 0.024 \\
\hline No & $177(80.8)$ & $24.37 \pm 3.828$ & & & $49.88 \pm 7.49$ & & \\
\hline
\end{tabular}

$P$ value $<0.05$ is significant. 


\section{Discussion and Conclusions}

This study was conducted with the expectation to identify high risk sexual behavior, knowledge, attitude and prevention practice with regard to HIV/AIDS among male workers working in factories manufacturing alcohol in Myanmar. In this study, the numbers of male workers were significantly higher than female workers in alcohol factories. The risk of HIV infection is high in male dominated profession and working in geographically isolated environment with limited social interaction and health facilities [13]. Moreover, previous studies have shown that factory workers have higher rate of alcohol consumption [14,15] and the people who abuse alcohol are more likely to engage in high risk sexual behaviors which can make them prone to HIV and other sexually transmitted diseases (STDs) [14,16]. In this study, twothird of the respondents consumed alcohol and half of them had intercourse after consuming alcohol. One-third of the workers could procure alcohol product from their factories at lower price and it was found to be one of the most important factor responsible for alcohol consumption. Heavy alcohol use has been correlated with a lifetime tendency toward high-risk behaviors including multiple sex partners, drug abuse, unprotected intercourse, having intercourse with high-risk partners and the exchange of sex for money or drugs [14,17,18].

Previous study has shown that sexual behavior might also be influenced by life experiences and urbanization [19]. In this study, nearly half of the workers migrated from other areas. Many of the respondents engaged in high risk sexual behavior such as extramarital intercourse, intercourse with casual partner and commercial sex workers, and homosexual relationships. Work related factors such as mobility of workers and separation away from families increase the risk of HIV infection [7]. Urbanization (e.g., from rural areas to urban areas or Industrial sites) creates a greater chance of mixing of diverse people at places of destination, which in turn causes a risk or disposed environment for HIV and STDs transmission $[19,20]$. Though use of condom is a key component of HIV prevention [10,21], in this study, most of the respondents who engaged high risk sexual behavior did not use condom consistently.

The results show that knowledge and attitude about HIV/AIDS were not significantly different between the male alcohol factory workers who used condom consistently and who did not use. This finding was consistent with other studies that showed knowledge did not always translate into practice $[19,22]$. Similar to another study [23], there was significantly lower knowledge about HIV/AIDS among respondents who engaged in high risk sexual behavior. Since knowledge, attitude and beliefs of sexual behaviors regarding HIV/AIDS are important in prevention of HIV transmission; limited knowledge among vulnerable population could lead to the rapid spread of HIV/AIDS [10].

Numerous studies have shown that one of the contributing factors for HIV/AIDS prevention and control is the mass media [24]. This study also indicates that information related to HIV/AIDS has reached mainly by mass media including television, newspaper, magazine and books. However, this population had a lower level of knowledge about HIV/AIDS as mass media in Myanmar does not provide enough information related to $\mathrm{HIV} /$ AIDS. Apart from mass media, workplace is one of the most important places for transmitting health knowledge and promoting consistent condom use among workers [25]. In this study, only half of the workers received HIV/AIDS related knowledge at their workplace mainly from their peers followed by supervisor, manager and owner.

The study highlights the need of peer education in prevention program of HIV/AIDS among factory workers to modify their knowledge, attitude, belief and behavior as it could affect change at the individual, group and societal level. Since owners and managers were keys to success and sustainability of the prevention programs at workplace, collaboration between them and health organization should be carried out for providing health education as well as for offering voluntary counseling and testing for HIV and STDs. Moreover, free or affordable condoms should be provided to this high risk population, and information, education and communication network should be established to support risk-reduction behavior for the beneficiaries.

This study has some limitations. Since the male workers from alcohol factories in Industrial Zone (A) in Mandalay were included in this study, the sample might not be representative of the factory workers in Myanmar. Secondly, as a cross-sectional study, this study could neither observe the changes over time or inference of causality.

\section{Acknowledgements}

The authors would like to express our gratitude to Dr. Usaneya Perngparn (Assistant Dean, College of Public Health Sciences, Chulalongkorn University) for her encouragement, support and guidance throughout the study. We would like to acknoweldge Dr. Khin Aye Aye (Executive Director, Myanmar Business Coalition on AIDS) and Dr. Htay Maung (Project Manager, Myanmar Business Coalition on AIDS), and the research assistants for their support for data collection. Last but not least, we would like to thank alcohol factories workers, managers 
and owners for their kind cooperation.

\section{REFERENCES}

[1] World Health Organization (WHO), "HIV/AIDS Fact sheet," 2012.

http://www.who.int/mediacentre/factsheets/fs360/en/index. $\mathrm{html}$

[2] Centers for Disease Control and Prevention (CDC), "Basic information about HIV and AIDS," 2012. http://www.cdc.gov/hiv/topics/basic/index.htm

[3] Joint United Nations Programme on HIV/AIDS (UNAIDS), "Global HIV/AIDS Response: Epidemic Update and Health Sector Progress towards Universal Access, Progress Report 2011,”2011.

http://whqlibdoc.who.int/publications/2011/97892415029 86_eng.pdf

[4] Ministry of Health Myanmar, "National Strategic Plan on HIV and AIDS 2011-2015," 2011.

http://www.jhsph.edu/research/centers-and-institutes/cent er-for-public-health-and-human-rights/_pdf/NSP\%20Full \%20Book\%20Final.pdf

[5] Joint United Nations Programme on HIV/AIDS (UNAIDS), "HIV and AIDS Estimates (2011)," 2012.

http://www.unaids.org/en/regionscountries/countries/mya nmar/

[6] World Health Organization (WHO) \& Joint United Nations Programme on HIV/AIDS (UNAIDS), "AIDS Epidemic Update: Special Report on HIV/AIDS: December 2006," 2006.

http://data.unaids.org/pub/epireport/2006/2006_epiupdate _en.pdf

[7] Environment and Social Development Department, International Finance Corporation, World Bank Group, "Good Practice Note: HIV/AIDS in the workplace," Good Practice Note, 2002.

http://www1.ifc.org/wps/wcm/connect/6eaa6500488555c 1b7f4f76a6515bb18/HIVAIDSEng.pdf?MOD=AJPERES

[8] World Health Organization (WHO), United Nations Programme on HIV/AIDS (UNAIDS) \& United Nations Children Funds (UNICEF), "Epidemiological Fact Sheet on HIV and AIDS. Core Data on Epidemiology and Response, Myanmar: 2008 Update," 2009.

http://www.who.int/hiv/pub/epidemiology/pubfacts/en/

[9] HIV and AIDS Data Hub for Asia-Pacific, "Vulnerability and HIV Knowledge, Myanmar," 2011.

http://www.slideboom.com/presentations/316684/Myanm ar\%E2\%80\%AA-\%282011\%29\%3A-\%E2\%80\%ACVuln erability-and-HIV-Knowledge

[10] Joint United Nations Programme on HIV/AIDS (UNAIDS), "Position Statement on Condoms and HIV Prevention," 2004.

http://data.unaids.org/pub/BaseDocument/2009/20090318 position_paper_condoms_en.pdf

[11] Wikipedia, "Mandalay: Demographic," 2012. http://en.wikipedia.org/wiki/Mandalay\#cite_note-un-3

[12] Y. Taro, "Statistics, an Introductory Analysis," 2nd Edi- tion, Harper and Row, New York, 1967.

[13] International Labor Organization (ILO), "Labour and Social Trend in Asia and the Pacific 2006: Progress towards Decent Work," 2006.

http://www.ilo.org/public/english/region/asro/bangkok/14 arm/download/labour.pdf

[14] R. M. Malow, J. G. Devieux, T. Jennings, B. A. Lucenko and S. C. Kalichman, "Substance Abusing Adolescent at Varying Level of HIV Risk: Psychosocial Characteristics, Drug Use and Sxual Behavior," Journal of Substance Abuse, Vol. 13, No. 1-2, 2001, pp. 103-117. doi:10.1016/S0899-3289(01)00069-4

[15] R. Khampang, J. Yothasamut, C. Putchong, S. Pilasant, S. Teeraananchai, S. Tantivess and Y. Teerawattananon, "The Drinking Behavior or Residents of a Village in an Industrial Park Area: The Current Situation and Reasons Behind This Behavior," 2012.

http://www.valueinhealthjournal.com/article/S1098-3015 $\% 2811 \% 2973273-9 /$ abstract

[16] E. Buregyeya, W. Bazeyo, B. E. Moen, C. Michelo and K. Fylkesnes, "HIV Risk Behavior and Work in Uganda: A Cross-Sectional Study," East African Journal of Public Health, Vol. 5, No. 1, 2008, pp. 43-48. doi:10.4314/eajph.v5i1.38976

[17] C. Therese, H. H. Pune and K. Archavantikul, "Sexuality, Reproductive Health and Violence: Experiences of Migrants from Burma in Thailand," Institute for Population and Social Research, Mahidol University, Bangkok, 2009. http://whothailand.healthrepository.org/handle/12345678 9/1116

[18] P. Mu, "Factors Affecting Sage Sex Behavior towards HIV/AIDS among Myanmar Reproductive Age Migrants in Muan District, Samutsakhon Province, Thailand," Master Dissertation, Assumption University, Bangkok, 2006.

[19] M. Thu, "Knowledge, Attitude and Practices Regarding Prevention of HIV/AIDS TRANSMISSION in Myanmar migrant Factory Workers in Mhachai District, Samutsakorn Province, Thailand," Master Dissertation, Chulalongkorn University, Bangkok, 2003.

[20] R. Machekano, M. Mbizvo, D. Katzenstein, M. Bassett, P. Zhou and A. Latif, "HIV Seroincidence and Correlates of Seroconversion in a Cohort of Male Factory Workers in Harare, Zimbabwe," AIDS, Vol. 10, 1996, pp. 895-901. doi:10.1097/00002030-199607000-00013

[21] K. K. Holmes, R. Levine and M. Weaver, "Effectiveness of Condoms in Preventing Sexually Transmitted Infections," Bulletin of the World Health Organization, Vol. 62, No. 6, 2004, pp. 454-461.

[22] F. S. Vaz, A. M. Ferreira, M. S. Kulkami and D. D. Motghare, "Sexual Behaviors and HIV/AIDS among Males in a Rural Community in Goa," Journal of Communicable Diseases, Vol. 38, No. 1, 2006, pp. 74-78.

[23] J. P. Hargreaves, C. P. Bonell, L. Morison, J. C. Kim, G. Phetla and J. D. Porter, "Explaining Continues High HIV Prevalence in South Africa: Socioeconomic Factors, HIV Incidence and Sexual Behaviors Change among a Rural Cohort, 2001-2004," AIDS, Vol. 21, Suppl. 7, 2007, pp. S39-S48. doi:10.1097/01.aids.0000300534.97601.d6 
[24] S. Liu, K. Wang, S. Yao, X. Guo, Y. Liu and B. Wang, "Knowledge and Risk Behaviors Related to HIV/AIDS and Their Association with Information Resource among Men Who Have Sex with Men in Heilongjang Province, China," BMC Public Health, Vol. 10, 2012, p. 250.

www.biomedcentral.com/1471-2458/10/250

doi:10.1186/1471-2458-10-250
[25] P. S. Win, "Prevalence and Determinants of Access to, Perceptions on, and Preferences for, HIV-Related Health Education among Myanmar Migrant Workers in Ranong, Thailand," Master Dissertation, Chulalongkorn University, Bangkok, 2007. 